\title{
Sistem Informasi Rekam Medis Puskesmas Kotaratu Berbasis Desktop
}

\author{
Aprilia Ningsi*1, Kristina Sara ${ }^{2}$, Anastasia Mude ${ }^{3}$ \\ 1,2,3 Program Studi Sistem Informasi, Universitas Flores \\ email: aprilianingsi098@gmail.com ${ }^{* 1}$, kristinasara27@gmail.com ${ }^{2}$, annmude87@gmail.com ${ }^{3}$ \\ (Received: 28 Oktober 2021 / Accepted: 29 November 2021 / Published Online: 20 Desember 2021)
}

\begin{abstract}
Abstrak
Proses administrasi pada puskesmas Kotaratu masih menggunakan cara manual. Sehingga memerlukan waktu yang cukup lama dalam menangani kunjungan pasien dan pembuatan laporan. Tujuan penelitian ini adalah membangun sistem informasi rekam medis berbasis dekstop menggunakan Bahasa Pemrograman Microsoft Visual Basic.Net serta MySQL sebagai databasenya. Teknik pengumpulan data melalui wawancara, observasi dan studi pustaka. Sedangkan, untuk mengembangkan perangkat lunak (sistem) dengan metode waterfall, sedangkan pengujian sistem menggunakan blackbox testing. Hasil temuan kami berupa sistem informasi berbasis dekstop di puskesmas kotaratu. Selanjutnya, hasil blackbox testing menunjukkan bahwa semua komponen pada sistem ini berjalan dengan baik, dan semua data rekam medis sudah tersimpan dalam database sehingga memberikan kemudahan dalam mengelola data pasien, mencari rekam medis, mengelola catatan rekam medis serta membuat laporan secara berkala.
\end{abstract}

Kata kunci: Rekam Medis, MySQL, Sistem Informasi, Waterfall, Blackbox Testing

\begin{abstract}
The administrative process at kotaratu health center still uses manual means. So, it takes a long time in handling patient visits and making reports. The goal of the study was to build a desktop-based medical record information system using the Microsoft Visual Basic. Net Programming Language and MySQL as its database. Data collection techniques through interviews, observations and literature studies. Meanwhile, to develop software (system) with waterfall method, while testing uses blackboxtesting. Our findings are in the form of a desktop-based information system at Kotaratu health center. Furthermore, Blackbox-testing results show that all components in this system are running well, and all medical record data is stored in the database to provide a convenience in managing patient data, searching for medical records, managing medical records and making reports periodically.
\end{abstract}

Keywords: Medical Records, MySQL, Information System, Waterfall, Blackbox Testing

\section{PENDAHULUAN}

Teknologi informasi dikala ini berkembang sangat pesat ialah mempermudah pengguna dalam menerima informasi dengan cepat. Dengan kemajuan teknologi membuat segala pekerjaan dan kegiatan manusia dalam meningkatkan kualitas diri semakin dipermudah (Wagiran \& Wisnawati, 2020). Adapula kebutuhan penggunaannya dalam bentuk yang berbeda, semacam komunikasi, pendidikan, bisnis, hiburan, ekonomi dan kesehatan. Salah satu contoh penggunaannya dalam bidang kesehatan yaitu sistem informasi pencatatan rekam medis (Ramadani et al., 2019).

Dalam penjelasan pasal 46 ayat (1) UU Praktik Kedokteran yang dimaksud dengan rekam medis adalah berkas yang berisi catatan dan dokumen antara lain identitas pasien, pemeriksaan peserta tindakan dan pelayanan lain yang diberikan kepada pasien pada sarana pelayanan kesehatan (Dewi et al., 2020). Data rekam medis merupakan data yang bersifat pribadi dan menjadi salah satu informasi penting bagi pasien pada saat menjalani pelayanan kesehatan (Ilmananda et al., 2020). Manfaat rekam medis sebagai pengobatan, peningkatan kualitas 
pelayanan, pendidikan dan penelitian, pembiayaan, statistik kesehatan, pembuktian masalah hukum, disiplin dan etik (Putranto et al., 2017).

Puskesmas merupakan satu kesatuan fungsional yang merupakan pusat pengembangan kesehatan masyarakat dan membina peran serta masyarakat, disamping memberikan pelayanan secara menyeluruh dan terpadu kepada masyarakat diwilayah kerjanya dalam bentuk kegiatan pokok (Wijaya, 2017). Puskesmas Kotaratu merupakan salah satu puskesmas yang ada di Kabupaten Ende guna memberikan pelayanan kesehatan terhadap masyarakat di Kota Ende. Pelayanan kesehatan merupakan suatu aktivitas yang tidak kasat mata sifatnya, dan terjadi antara interaksi petugas dan pasien (Andrianto \& Nursikuwagus, 2017). Dalam proses pencatatan dan penyimpanan data rekam medis pasien pada Puskesmas Kotaratu dilakukan dengan menggunakan buku besar. Sehingga kurang efisien untuk jangka panjang karena menggunakan media kertas dimana data akan semakin bertambah dan menumpuk pada rak penyimpanan (Ramadhan \& Fajarita, 2018) sehingga membutuhkan tempat yang cukup luas untuk menyimpannya. Disebabkan pencatatan masih dilakukan menggunakan buku besar, sehingga dalam pembuatan laporan masih banyak ditemui hambatan seperti waktu pembuatan laporan yang lama serta kesalahan pencatatan sehingga menimbulkan hasil dari laporan menjadi kurang optimal.

Sistem informasi merupakan sistem yang dapat dikatakan dengan mengumpulkan, memproses, dan menyebarkan informasi untuk tujuan tertentu. Seperti sistem lainnya, sistem informasi terdiri dari input, proses, dan output (Ramadhan \& Fajarita, 2018). Agar memudahkan petugas dalam memberikan pelayanan kesehatan terhadap masyarakat, maka pada penelitian ini membangun sebuah sistem informasi rekam medis berbasis dekstop dengan menggunakan metode pengembangan waterfall serta bahasa pemrograman Microsoft Visual Basic.Net dan MySQL sebagai databasenya. Penelitian terkait tentang Sistem informasi rekam medis sudah dilakukan oleh beberapa peneliti antara lain penelitian (Ilmananda et al., 2020). Mereka mengembangkan sistem informasi rekam medis berbasis desktop dengan metode waterfall. Sistem tersebut dibangun untuk mempermudah kinerja karyawan dalam proses pengolahan data pasien dan membuat laporan, khususnya pada bagian loket yang menjadi tempat penyimpanan rekam medis seluruh pasien yang terdaftar dirumah sakit. Selain itu, Dewi et al., (2020) mengembangkaan sistem menggunakan metode waterfall, sebagai servernya Apache 2.4.34, bahasa pemrograman php 5.6.38 dan MySQL sebagai database dengan tujuan memudahkan pihak puskesmas mengolah data pasien dan rekam medis pasien sehingga menjadi laporan.

Berdasarkan tersebut di atas, tujuan penelitian ini mengembangkan sistem rekam medis berbasis desktop juga, namun di tempat yang berbeda. Sehingga, dengan adanya sistem informasi rekam medis ini bertujuan untuk meningkatkan pelayanan kesehatan di Puskesmas Kotaratu, seperti pengolahan data pasien dan pembuatan laporan rekam medis menjadi lebih efektif dan efisien. Disamping ini penulis bukan hanya membangun aplikasi sistem informasi berbasis dekstop,tetapi juga memberikan pelatihan kepada pengguna (petugas kesehatan) agar lebih memahami dan mudah dalam mengakses aplikasi ini.

\section{METODE}

Metode Waterfall merupakan suatu model proses terstruktur dalam mengembangkan perangkat lunak yang bersifat linear dari tahap awal perencanaa sampai tahap akhir pemeliharaan (Zendrato, 2020). Terdapat 5 tahapan pada metode waterfall (lihat gambar 1), yaitu requirement analysis and definition, system and software design, implementation and unit testing, integration and system testing, dan operation and maintenance (Afuan et al., 2021; Fadhlurrahman \& Capah, 2020; Rizki \& Mulyati, 2020; Sasmito, 2017). 


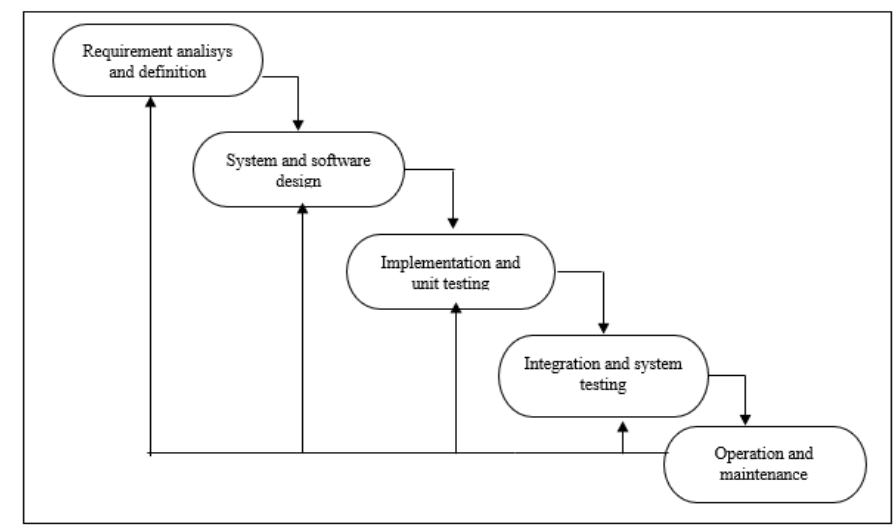

Gambar 1. Tahapan-tahapan Metode Waterfall

Berdasarkan gambar 1 tersebut, pada tahap pertama yaitu tahap Requirement analysis and definition, melaksanakan analisis terhadap sistem lama yang berjalan di Puskesmas Kotaratu agar bisa mengusulkan sebuah sistem baru yang diharapkan mampu melakukan tugas yang belum mampu dilakukan sistem lama. Kedua tahap System and software design, setelah melakukan analisis terhadap sistem lama yang berjalan, kemudian merancang design sistem yang akan diusulkan. Design sistem pada penelitian ini menggunakan Flowchart, Context Diagram, Data Flow Diagram, Entity Relationship Diagram. Ketiga Implemetation and unit testing merupakan tahapan mengimplementasikan dari tahap design dimana dilakukan evaluasi untuk mengurangi kesalahan dengan menjalankan kode yang dibuat. Peneliti melakukan pengkodingan sistem menggunakan bahasa pemrograman Visual Basic.Net. Keempat Integration and system testing, tahap pengujian testing ini menggunakan metode Blackbox testing untuk mengetahui kekurangan ataupun kesalahan pada saat melakukan pengkodingan (Anggoro \& Hidayat, 2020; Kusrini et al., 2020). Agar mengetahui sistem yang diusulkan bekerja dengan baik sehingga mampu membantu mengatasi masalah pengolahan data rekam medis pada Puskesmas Kotaratu. Tahap terakhir yaitu Operation and maintenance, dimana sistem yang sudah dibangun dengan baik dan kami memberikan arahan terhadap peneliti selanjutnya agar bisa melakukan penambahan fitur baru yang belum ada pada sistem ini.

Metode yang digunakan untuk mengumpulkan data dalam penelitian ini meliputi observasi, wawancara, dan studi pustaka. Observasi dengan cara melakukan pengamatan langsung terhadap puskesmas Kotaratu untuk mengetahui keadaan objek penelitian yang sebenarnya dengan tujuan untuk memperoleh informasi yang jelas mengenai sistem informasi rekam medis yang ada disana. Data yang dikumpulkan dari hasil observasi berupa data rekam medis pasien, data poliklinik data apotek dan alur sistem pelayanan mulai pendaftaran sampai pengambilan obat. Sedangkan teknik wawancara kami melakukan wawancara secara langsung dengan salah satu petugas medis untuk mendaptkan informasi yang dibutuhkan dalam penelitian. Sementara itu studi pustaka, penulis mengumpulkan data dan informasi melalui referensi berbentuk buku-buku, makalah, jurnal serta browsing internet yang dapat dijadikan landasan teori.

Metode pengujian yang digunakan dalam penelitian ini yaitu Blackbox testing. Blackbox testing yaitu pengujian kualitas yang dilakukan untuk memastikan fungsionalitas pada perangkat lunak yang dibangun (Aliero et al., 2020; Cabana et al., 2019; Munthe et al., 2020; Setiyani, 2019; Verma et al., 2017). Pengujian Blackbox testing dengan teknik aquivalence partition, yaitu teknik dengan menguji memecahkan atau membagi domain input dari program kedalam kelas-kelas data sehingga test case yang diperoleh dinilai cukup relevan. Teknik pengujian ini dilakukan untuk memastikan bahwa masing-masing fungsi berjalan dengan sepenuhnya (Amiri et al., 2021; Groz et al., 2020; Sun et al., 2021) dan mencari kesalahan pada setiap fungsi yang berfokus pada memasukkan sistem data, tampilan, pemakaian memori dan 
kecepatan eksekusi data, sehingga jika memasukkan data tidak sesuai dengan yang diharapkan maka sistem gagal (Walter et al., 2020).

\section{HASIL DAN PEMBAHASAN \\ Hasil}

Hasil dari penelitian ini sudah tercapai dengan membangun sebuah aplikasi sistem informasi rekam medis berbasis dekstop yang mana semua data rekam medis sudah teersimpan dalam sebuah database sehingga memberikan kemudahan dalam pengelolaan rekam medis seperti mengelola data pasien, mencari rekam medis, mengelola catatan rekam medis, serta memudahkan dalam membuat laporan kunjungan loket, laporan diagnosa pasien dan laporan kunjungan apotek secara berkala.

Desain sistem merupakan penyusunan perangkat lunak baru untuk menggantikan peran sistem lama atau secara keseluruhan berguna untuk memperbaiki kelemahan yang ada pada sistem lama (Labuhanbatu \& Berbasis, 2020). Desain sistem pada penelitian ini menggunakan context diagram dan data flow diagram seperti pada gambar 2 dan gambar 3.Context Diagram merupakan diagram yang menggambarkan tentang keseluruhan perangkat lunak dan menyertakan terminator yang terlibat dalam penggunaan perangkat lunak (Kusmanto, 2018). Contect Diagram pada gambar 2 menjelaskan secara garis besar jalannya data atau informasi keseluruhan kepada pengguna, yaitu admin, petugas loket, petugas poli dan petugas apotek.

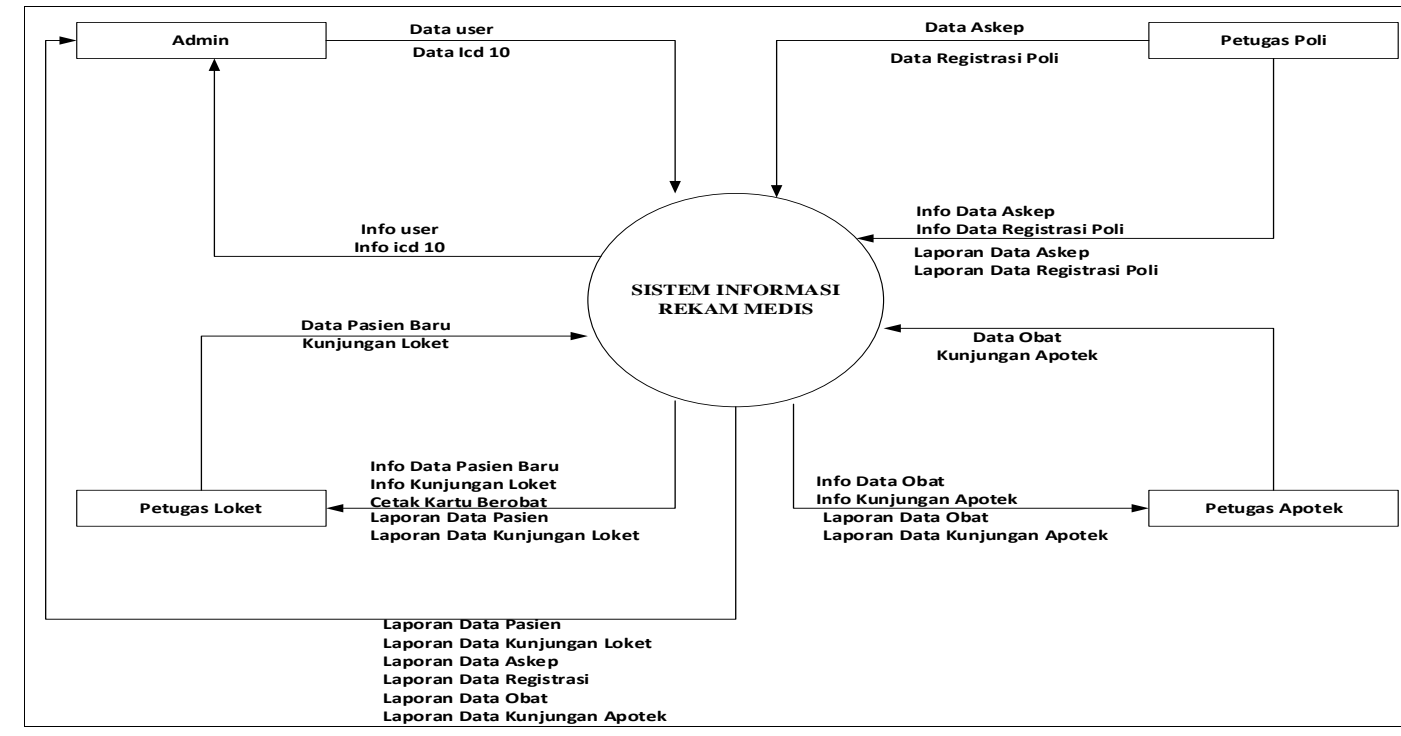

Gambar 2. Context Diagram

Data Flow Diagram merupakan model logika yang menggambarkan arus data dalam suatu perusahaan dengan sejumlah simbol untuk menunjukan perpindahan data yang terjadi dalam proses suatu bisnis (Muliadi et al., 2020). Data Flow Diagram pada gambar 3 menjelaskan secara rinci dari kerja sistem dengan membagi kedalam beberapa proses yang saling berkaitan dan disimpan dalam database masing-masing.

Implementasi antarmuka dilakukan dengan setiap tampilan program yang dibangun. Implemetasi antarmuka (interface) perancangan sistem informasi rekam medis Puskesmas Kotaratu menggunakan metode waterfall yang dibuat yang terdiri dari menu login, menu input data user, menu cetak kartu berobat, dan menu kunjungan loket. Login merupakan tampilan awal sistem yang akan ditampilkan kepada pengguna. Sebelum pengguna masuk ke dalam sistem harus login terlebih dahulu dengan menginputkan username dan password. Tampilan login pada sistem ini nampak pada gambar 4. 


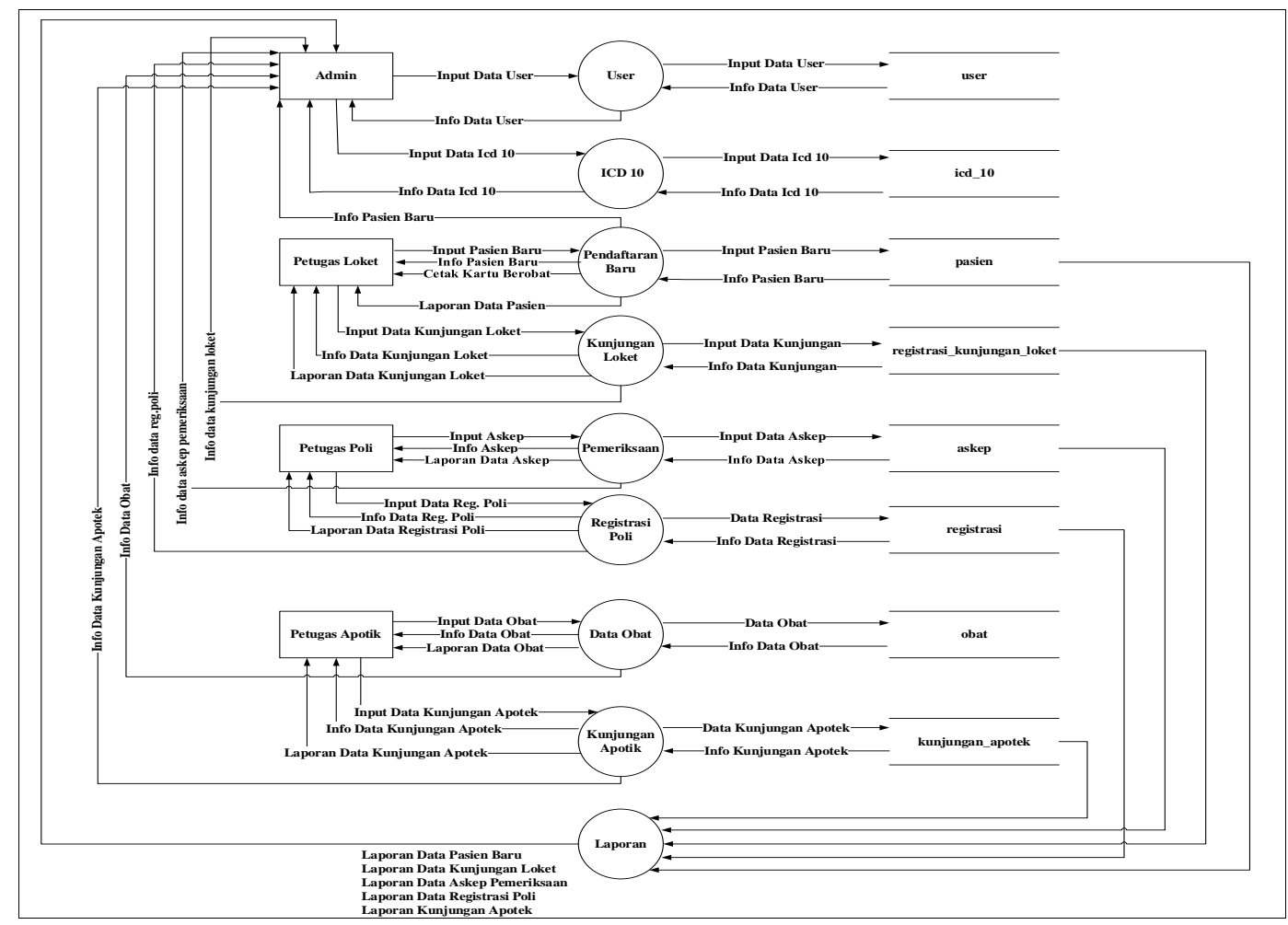

Gambar 3. Data Flow Diagram

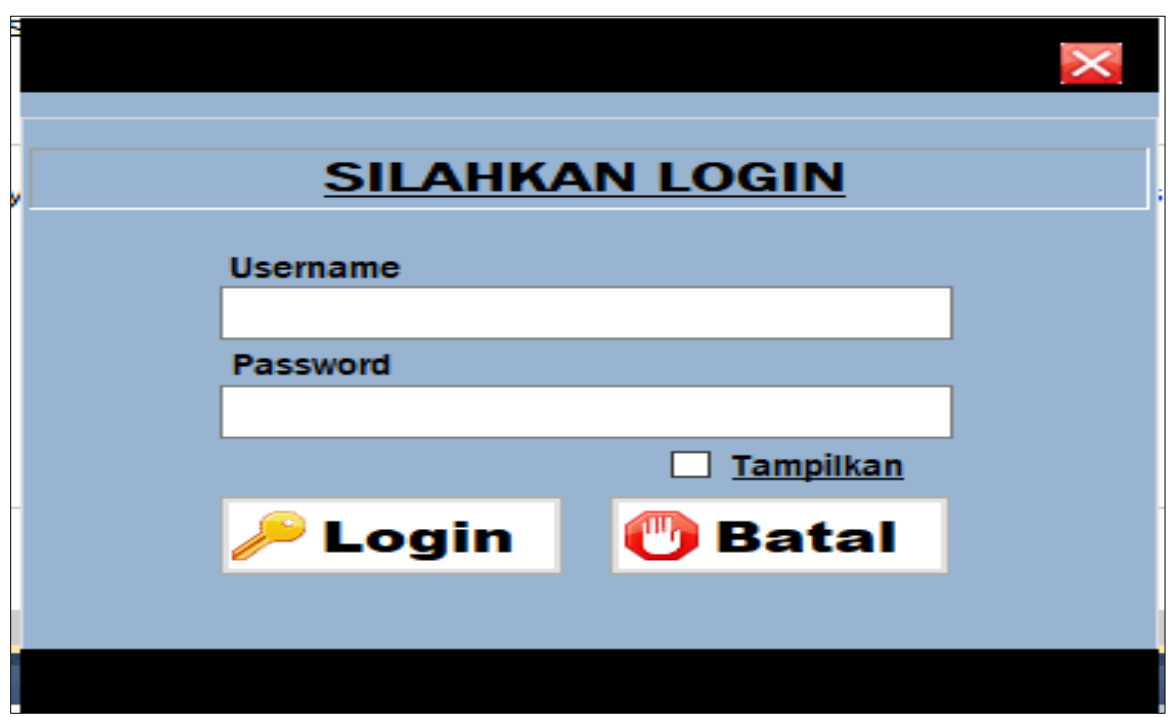

Gambar 4. Tampilan Menu Login

Selanjutnya pada menu input data user yang terlihat pada gambar 5, berfungsi untuk mengolah data user yang terlibat pada puskesmas Kotaratu. Data user diinput oleh bagian admin kedalam database rekam medis melalui form user. Pada form pasien dan saat menampilkan data pasien petugas (lihat gambar 5) dapat mencetak kartu berobat. Pada saat akan mencetak kartu berobat, maka sistem akan menampilkan desain kartu berobat. Pada menu input kunjungan loket berfungsi untuk menginput data pasien yang berkunjung baik pasien lama maupun pasien baru (pasien yang sudah terdaftar) yang akan berobat. Tampilan form ini dapat dilihat pada gambar 7 . 


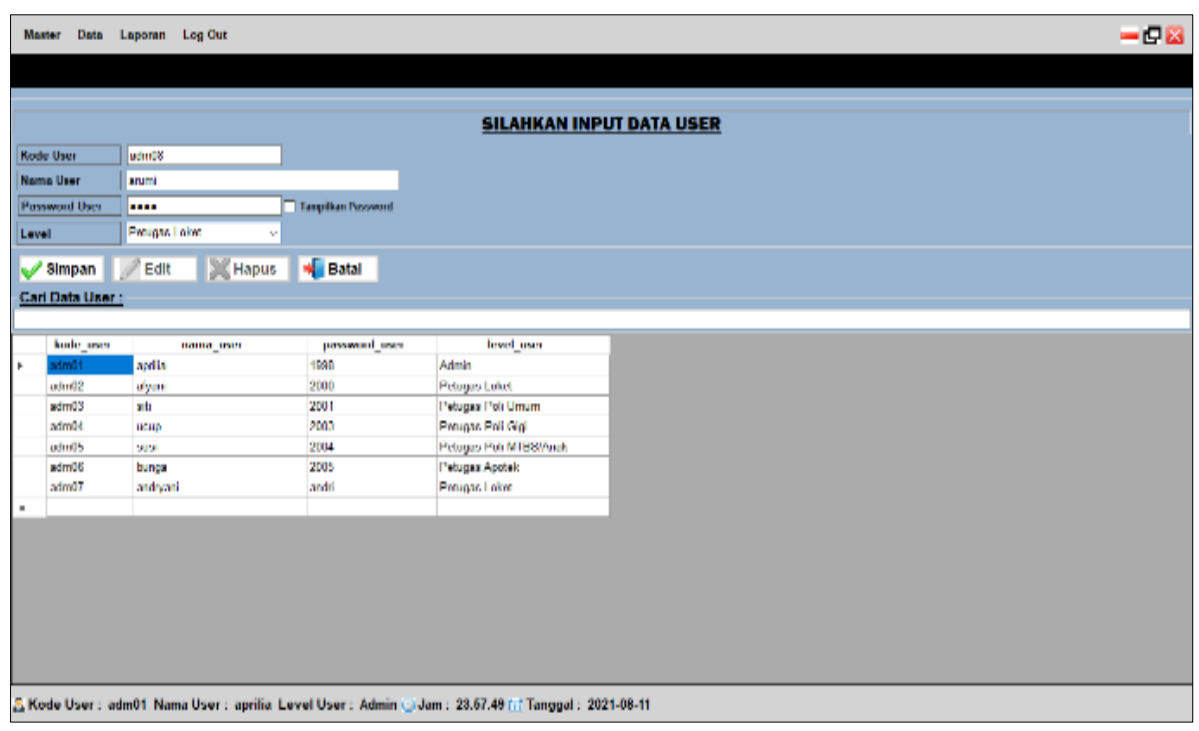

Gambar 5. Tampilan Menu Input Data User

Tahap selanjutnya adalah pengujian, dimana sistem ini diuji menggunakan blackbox testing dan dilakukan oleh pengguna tersebut. Pengguna memasuki sistem dan bertindak selaku sistem administrator kemudian melakukan pengujan dengan perolehan hasil seperti pada tabel 1. Berdasarkan hasil akhir pengujian menggunakan metode blackbox testing tidak ditemukan adanya error pada setiap proses pengujian fungsionalitas aplikasi yang dibangun.

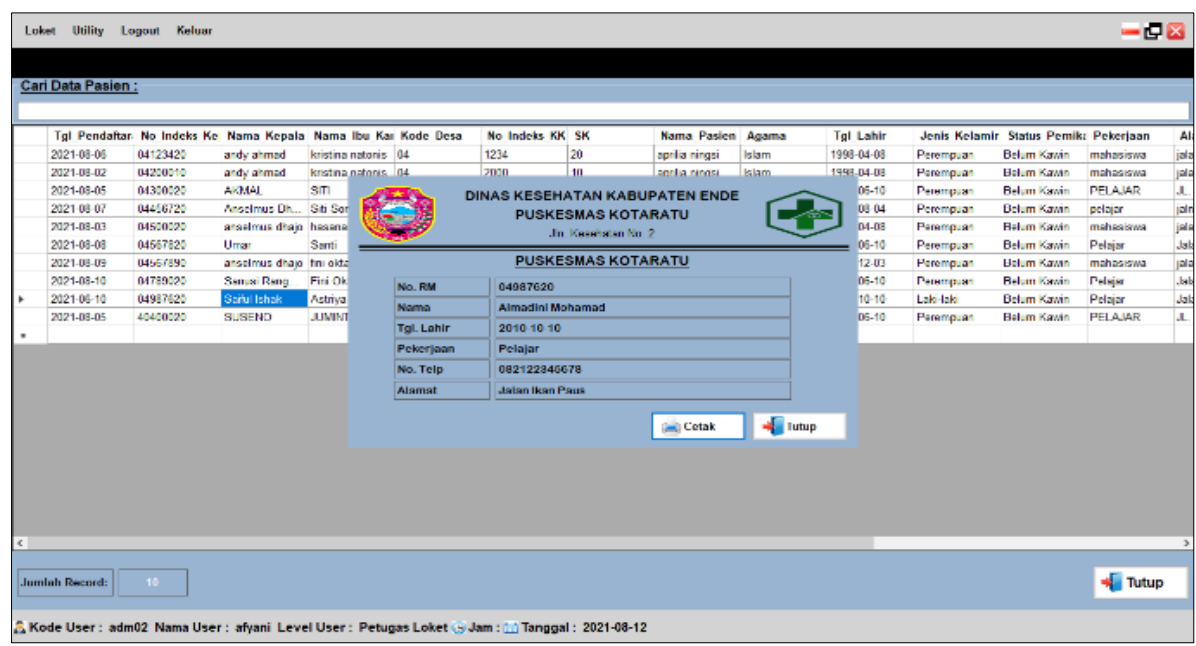

\section{Pembahasan}

Gambar 6. Tampilan Menu Cetak Kartu Berobat

Proses pengolahan data rekam medis pada puskesmas Kotaratu yang sebelumnya masih dilakukan secara manual, kini sudah dibangun dan dikembangkan menjadi sebuah aplikasi sistem informasi berbasis desktop. Pada gambar 2 bisa dilihat bahwa sistem informasi rekam medis dikembangkan dan dirancang dengan 4 level pengguna yaitu, petugas admin, petugas loket, petugas poli, dan petugas apotek. Rancangan masukkan, proses dan keluaran dapat dilihat pada gambar 3. Pada sistem informasi rekam medis ini admin, petugas loket, petugas poli dan petugas apotek saling berinteraksi melalui proses 1.0 sampai 9.0 seperti yang ditampilkan pada gambar 3. 


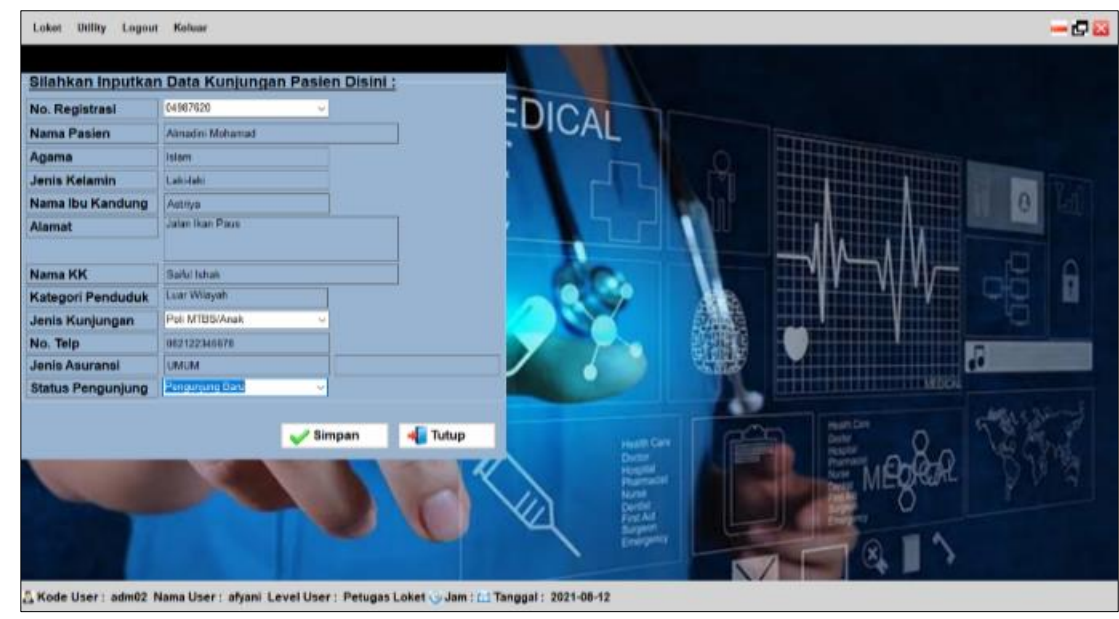

Gambar 7. Tampilan Menu Input Kunjungan Loket

Tabel 1. Hasil Pengujian Sistem dengan BlackBox Testing

\begin{tabular}{|c|c|c|c|}
\hline Cara Pengujian & Hasil yang Diharapkan & Pengamatan & Keterangan \\
\hline $\begin{array}{c}\text { Masukan username } \\
\text { dan password } \\
\text { dengan benar }\end{array}$ & $\begin{array}{l}\text { Akan menampilkan halaman } \\
\text { utama }\end{array}$ & $\begin{array}{c}\text { Menampilkan } \\
\text { halaman utama }\end{array}$ & Berhasil \\
\hline $\begin{array}{l}\text { Input data user } \\
\text { dengan benar }\end{array}$ & $\begin{array}{l}\text { Akan menampilkan pesan } \\
\text { data berhasil diinput }\end{array}$ & $\begin{array}{l}\text { Menampilkan Pesan } \\
\text { data berhasil diinput }\end{array}$ & Berhasil \\
\hline $\begin{array}{l}\text { Kosongkan data user } \\
\text { lalu klik simpan }\end{array}$ & $\begin{array}{l}\text { Akan menampilkan pesan } \\
\text { field tidak boleh kosong }\end{array}$ & $\begin{array}{l}\text { Menampilkan pesan } \\
\text { field tidak boleh } \\
\text { kosong }\end{array}$ & Berhasil \\
\hline Input data ICD 10 & $\begin{array}{c}\text { Akan menampilkan pesan } \\
\text { data berhasil disimpan }\end{array}$ & $\begin{array}{c}\text { Menampilkan pesan } \\
\text { data berhasil } \\
\text { disimpan }\end{array}$ & Berhasil \\
\hline $\begin{array}{l}\text { Kosongkan data ICD } \\
10 \text { lalu klik simpan }\end{array}$ & $\begin{array}{l}\text { Akan menampilkan pesan } \\
\text { field tidak boleh kosong }\end{array}$ & $\begin{array}{l}\text { Menampilkan pesan } \\
\text { field tidak boleh } \\
\text { kosong }\end{array}$ & Berhasil \\
\hline Edit data ICD 10 & $\begin{array}{c}\text { Akan menampilkan pesan } \\
\text { data berhasil diupdate }\end{array}$ & $\begin{array}{c}\text { Menampilkan pesan } \\
\text { data berhasil } \\
\text { diupdate }\end{array}$ & Berhasil \\
\hline Hapus data ICD 10 & $\begin{array}{l}\text { Akan menampilkan pesan } \\
\text { data berhasil dihapus }\end{array}$ & $\begin{array}{l}\text { Menampilkan pesan } \\
\text { data berhasil dihapus }\end{array}$ & Berhasil \\
\hline $\begin{array}{l}\text { Input data pasien } \\
\text { baru dengan benar }\end{array}$ & $\begin{array}{l}\text { Akan menampilkan pesan } \\
\text { data berhasil disimpan }\end{array}$ & $\begin{array}{c}\text { Menampilkan pesan } \\
\text { data berhasil } \\
\text { disimpan }\end{array}$ & Berhasil \\
\hline $\begin{array}{c}\text { Kosongkan data } \\
\text { pasien baru lalu klik } \\
\text { simpan }\end{array}$ & $\begin{array}{l}\text { Akan menampilkan pesan } \\
\text { field tidak boleh kosong }\end{array}$ & $\begin{array}{l}\text { Menampilkan pesan } \\
\text { field tidak boleh } \\
\text { kosong }\end{array}$ & Berhasil \\
\hline $\begin{array}{c}\text { Input data pasien } \\
\text { kunjungan loket klik } \\
\text { simpan }\end{array}$ & $\begin{array}{l}\text { Akan menampilkan pesan } \\
\text { data pasien berhasil diinput }\end{array}$ & $\begin{array}{l}\text { Menampilkan pesan } \\
\text { data berhasil diinput }\end{array}$ & Berhasil \\
\hline Input askep & Askep berhasil diinput & $\begin{array}{l}\text { Menampilkan askep } \\
\text { berhasil diinput }\end{array}$ & Berhasil \\
\hline $\begin{array}{l}\text { Input data obat lalu } \\
\text { klik simpan }\end{array}$ & $\begin{array}{l}\text { Akan menampilkan pesan } \\
\text { data berhasil disimpan }\end{array}$ & $\begin{array}{c}\text { Menampilkan pesan } \\
\text { data berhasil } \\
\text { disimpan }\end{array}$ & Berhasil \\
\hline
\end{tabular}


Sistem informasi rekam medis ini dilengkapi dengan fitur login untuk masing-masing pengguna untuk menjaga keamanan data-data yang ada dan juga jika ada kesalahan dalam mengisi data pasien bisa langsung ketahui petugas siapa yang menangani data pasien tersebut. Jika dibandingkan dengan penelitian (Ilmananda et al., 2020) dan (Dewi et al., 2020), mereka mengembangkan sistem informasi pada rumah sakit dan puskesmas berbasis desktop dan web. Dimana, sistem tersebut dapat berjalan sebagaimana mestinya setelah dilakukan pengujian dengan blackbox testing. Selain itu, mereka menggunakan bahasa pemrograman Microsoft Visual Basic.Net ini memiliki beberapa fitur yang lebih baik dan lebih mudah diakses oleh pengguna. Sementara itu, hasil pengujian sistem yang dilakukan menggunakan Blackbox testing dengan teknik aquivalence partition dapat dilihat pada tabel 1 memperolah hasil yang memuaskan, yang artinya semua komponen sistem berjalan dengan baik. Oleh karena itu, berdasarkan hasil tersebut, sistem informasi rekam medis ini dapat dengan mudah dioperasikan oleh pengguna. Selain membangun aplikasi sistem informasi rekam medis, kami juga bisa memberikan pelatihan terhadap pengguna/petugas medis dalam mengoperasikan sistem tersebut.

\section{SIMPULAN}

Sistem informasi rekam berbasis dekstop ini bisa digunakan dengan mudah dan cepat bagi petugas medis dalam mengolah data pasien dan membuat laporan. Adapun saran untuk pengembangan sistem selanjutnya, yaitu didalam sistem ini belum tersedia surat rujukan/tindakan ke laboratorium, rumah sakit dan instansi kesehatan lainnya dan untuk mencegah serta mengindari rusak atau hilangnya data dalam file mengingat pentingnya sebuah data, maka diperlukan file duplikat (backup).

\section{REFERENSI}

Afuan, L., Nofiyati, N., \& Umayah, N. (2021). Rancang Bangun Sistem Informasi Bank Sampah di Desa Paguyangan. Edumatic: Jurnal Pendidikan Informatika, 5(1), 21-30.

Aliero, M. S., Ghani, I., Qureshi, K. N., \& Rohani, M. F. (2020). An algorithm for detecting SQL injection vulnerability using black-box testing. Journal of Ambient Intelligence and Humanized Computing, 11(1), 249-266.

Amiri, S. S., Mottahedi, S., Lee, E. R., \& Hoque, S. (2021). Peeking inside the black-box: Explainable machine learning applied to household transportation energy consumption. Computers, Environment and Urban Systems, 88, 101647.

Andrianto, P., \& Nursikuwagus, A. (2017). Sistem Informasi Pelayanan Kesehatan Berbasis Web di Puskesmas. Seminar Nasional Komputer Dan Informatika, 47-52.

Anggoro, D., \& Hidayat, A. (2020). Rancang Bangun Sistem Informasi Perpustakaan Sekolah Berbasis Web Guna Meningkatkan Efektivitas Layanan Pustakawan. Edumatic : Jurnal Pendidikan Informatika, 4(1), 151-160. https://doi.org/10.29408/edumatic.v4i1.2130

Cabana, A., Charrier, C., \& Louis, A. (2019). Mono and multi-modal biometric systems assessment by a common black box testing framework. Future Generation Computer Systems, 101, 293-303.

Dewi, B. R., Rahajo, S., \& Adhitya, E. (2020). Perancangan Sistem Informasi Puskesmas Berbasis Web. Jurnal IKRA-ITH Informatika, 4(103), 12-19.

Elektronika, J., Informasi, T., Ramadani, N., \& Yul, F. A. (2019). Perancangan Aplikasi Rekam Medis Pada Puskesmas Talang Tinggi. 1(2), 19-24.

Fadhlurrahman, M., \& Capah, D. (2020). Aplikasi Penyewaan Lapangan Futsal Berbasis Web. Edumatic: Jurnal Pendidikan Informatika, 4(2), 30-39. https://doi.org/10.29408/edumatic.v4i2.2412

Groz, R., Bremond, N., Simao, A., \& Oriat, C. (2020). hW-inference: A heuristic approach to retrieve models through black box testing. Journal of Systems and Software, 159, 110426. 
Ilmananda, A. S., Rizkianto, M. N., \& Marcus, R. D. (2020). Sistem Informasi Rekam Medis Berbasis Desktop untuk Rumah Sakit Umum Daerah KH Mansyur Kintap dengan VB . NET. Seminar Nasional Sistem Informasi, 2526-2533. Malang: Universitas Merdeka Malam

Kusmanto. (2018). Perancangan Aplikasi Pendataan Suplayer Getah Karet Pada Pt. Rubber Hock Lie Menggunakan Visual Basic.Net. Jurnal INFOTEK, 3(1), 1-9.

Kusrini, W., Fathurrahmani, F., \& Sayyidati, R. (2020). Sistem Pakar untuk Diagnosa Penyakit Ayam Pedaging. Edumatic: Jurnal Pendidikan Informatika, 4(2), 75-84.

Labuhanbatu, K. A. B., \& Berbasis, S. (2020). Musthafa Haris Munandar 1), Masrizal 2). 8(2), 59-64.

Muliadi, M., Andriani, M., \& Irawan, H. (2020). Perancangan Sistem Informasi Pemesanan Kamar Hotel Berbasis Website (Web) Menggunakan Data Flow Diagram (DFD). JISI: Jurnal Integrasi Sistem Industri, 7(2), 111-122. https://doi.org/10.24853/jisi.7.2.111-122

Munthe, I. R., Rambe, B. H., Pane, R., Irmayani, D., \& Nasution, M. (2020). UML Modeling and Black Box Testing Methods in the School Payment Information System. Jurnal Mantik, 4(3), 1634-1640.

Putranto, Y. Y., Wijanarko, T., Putra, A., \& Hakim, F. N. (2017). Rancang Bangun Sistem Informasi Rekam Medis Klinik berbasis Web (Studi Kasus: Klinik Utama Meditama Semarang). Jurnal Informatika Upgris, 3(2), 105-115.

Ramadhan, M. F., \& Fajarita, L. (2018). Pembuatan Aplikasi Sistem Informasi Administrasi Surat Menyurat Studi Kasus : Kesekretariatan Badan Eksekutif Mahasiswa Universitas Budi Luhur. IDEALIS: InDonEsiA JournaL Information System, 1(1), 106-112. https://jom.fti.budiluhur.ac.id/index.php/IDEALIS/article/view/126

Rizki, R., \& Mulyati, S. (2020). Implementasi One Time Password Menggunakan Algoritma SHA-512 Pada Aplikasi Penagihan Hutang PT. XHT. Edumatic: Jurnal Pendidikan Informatika, 4(1), 111-120.

Sasmito, G. W. (2017). Penerapan Metode Waterfall Pada Desain Sistem Informasi Geografis Industri Kabupaten Tegal. Jurnal Informatika: Jurnal Pengembangan IT, 2(1), 6-12.

Setiyani, L. (2019). Pengujian Sistem Informasi Inventory Pada Perusahaan Distributor Farmasi Menggunakan Metode Black Box Testing. Techno Xplore: Jurnal Ilmu Komputer Dan Teknologi Informasi, 4(1), 1-9. https://doi.org/10.36805/technoxplore.v4i1.539

Sun, F., Wang, L., \& Yang, B. (2021). A neuro-diversified benchmark generator for black box optimization. Information Sciences, 573, 475-492.

Verma, A., Khatana, A., \& Chaudhary, S. (2017). A Comparative Study of Black Box Testing and White Box Testing. Int. J. Comput. Sci. Eng, 5(12), 301-304.

Wagiran, \& Wisnawati. (2020). Perancangan Sistem Aplikasi Pendaftaran Rawat Jalan Di Puskesmas Tempunak Menggunakan Microsoft Access. Jurnal Perekam Medis Dan Informasi Kesehatan, 3(1), 14-19.

Walter, J., Manurung, H., Ferian, R. A., \& Faharrudin, W. (2020). Pengujian Black Box pada Aplikasi Sistem Informasi Pengelolaan Masjid Menggunakan Teknik Equivalence Partitions. 3(2), 107-113. https://doi.org/10.32493/jtsi.v3i2.4694

Wijaya, H. O. L. (2017). Penerapan Metode Waterfall Pada Sistem Informasi Pendaftaran Pasien Rawat Jalan Berbasis Web Mobile. Jurnal Sisfokom (Sistem Informasi Dan Komputer), 6(2), 80. https://doi.org/10.32736/sisfokom.v6i2.251

Zendrato, H. P. (2020). Perancangan Sistem Informasi Logistik Berbasis Web Pada PT . Unitama Huting Mandiri Menggunakan Metode Waterfall. REMIK (Riset Dan E-Jurnal Manajemen Informatika Komputer), 2(2), 19-35. https://jurnal.polgan.ac.id/index.php/remik/article/view/10837 